\title{
Transatlantica
}

Revue d'études américaines. American Studies Journal

\section{Gaïd Girard ed. Le Superflu, chose très nécessaire.}

Rennes : Presses Universitaires de Rennes, 2004. 290 p.

\section{Nathalie Vanfasse}

\section{(2) OpenEdition}

Journals

Édition électronique

URL : http://journals.openedition.org/transatlantica/838

DOI : $10.4000 /$ transatlantica.838

ISSN : $1765-2766$

Éditeur

AFEA

Référence électronique

Nathalie Vanfasse, "Gaïd Girard ed. Le Superflu, chose très nécessaire. », Transatlantica [En ligne], 1 | 2005, mis en ligne le 22 avril 2006, consulté le 29 avril 2021. URL : http://journals.openedition.org/ transatlantica/838; DOI : https://doi.org/10.4000/transatlantica.838

Ce document a été généré automatiquement le 29 avril 2021

\section{(c)}

Transatlantica - Revue d'études américaines est mis à disposition selon les termes de la licence Creative Commons Attribution - Pas d'Utilisation Commerciale - Pas de Modification 4.0 International. 


\title{
Gaïd Girard ed. Le Superflu, chose très nécessaire.
}

Rennes : Presses Universitaires de Rennes, 2004. 290 p.

\author{
Nathalie Vanfasse
}

1 Ces Actes d'un colloque organisé par le Centre d'Études Interdisciplinaires du Monde Anglophone à l'Université de Brest fin novembre 2002, rassemblés et présentés par Gaïd Girard offrent un volume riche et agréable à lire. L'ouvrage part du couple superflu/ nécessaire rendu célèbre par Voltaire et, en cinq parties, s'emploie avec succès à dépasser l'opposition entre ces deux termes.

2 La première partie, « Poétique et politique du superflu ", s'intéresse aux rapports entre superflu et écriture. Jean-Jacques Lecercle analyse l'usage luxueux que la littérature fait de la langue. Marie-Christine Agosto montre que la vie ascétique de Thoreau à Walden l'amène à définir le superflu comme une condition vitale de la liberté. Gilles Mayné applique au roman A Spy in the House of Love d'Anaïs Nin la théorie de Bataille sur les " dépenses improductives".

3 La seconde partie du recueil est intitulée "Les voies démultipliées du superflu». Elisabeth Soubrenie se penche sur le dilemme stylistique du superflu auquel est confronté Burton, tiraillé entre scolastique et baroque, dans son Anatomy of Melancholy. François Gavillon analyse la progression labyrinthique des romans de Paul Auster et s'interroge sur le caractère superflu de ces bifurcations. Florian Tréguer examine le traitement de l'excès sonore comme modalité du superflu dans White Noise de Don DeLillo. Gilles Ménégaldo montre que le cinéma de Woody Allen est marqué par le superflu qui prend la forme de citations cinématographiques, de dédoublements et de plans-séquences qui échappent à l'ordre logico-temporel de la narration.

4 Dans la troisième partie, " $\mathrm{Du}$ corps humain au corps social: une économie du superflu», Helen Moore souligne d'abord combien la question de l'équilibre est au centre de la pièce de Shakespeare The Merchant of Venice. Claire Crignon-De Oliveira offre ensuite une analyse de la mélancolie comme la maladie du superflu et de l'Angleterre comme le pays de la mélancolie. Annick Cossick montre que Bath au XVIIIe siècle proposait un remède aux excès du corps tout en encourageant la consommation 
effrénée de biens et de divertissements. Jean Boncœur s'attache à la notion de dépenses superflues dans la pensée économique anglaise et souligne le paradoxe qui veut que dépenses et excès contribuent à l'équilibre social. Anne Brunon-Ernst met en évidence l'existence d'un courant économique qui, lui, valorise l'épargne et trouve sa forme d'expression la plus achevée dans le traitement des pauvres proposé par Bentham dans les Poor Law Writings.

La quatrième partie de l'ouvrage "Fonctionnalité du superflu : figures de l'excentré " se concentre sur quelques figures typiques de la fin du XIXe siècle britannique qui relèvent du superflu. Hélène Machinal analyse Sherlock Holmes comme un personnage à la confluence d'un discours scientifique et central et d'un discours romanticoesthétique et excentré. Gilbert Pham-Thanh s'intéresse au dandy condamné implicitement dans les "fashionable novels " mais figure positive chez Wilde. AnnePascale Bruneau envisage la valeur de l'inutile dans les théories de l'art en GrandeBretagne, notamment dans la théorie de «l'Art pour l'Art » telle qu'elle fut exposée par Whistler.

6 La dernière partie du recueil, "Esthétique du superflu, débords et entre-deux » est consacrée aux phénomènes de débordement en art. Liliane Louvel explore les liens entre texte et image sous un angle nouveau à partir d'une question provocatrice: le discours est-il superflu à l'image ? Éric Gonzalez se fonde sur la nouvelle de Pynchon, Entropy, pour s'interroger sur la notion d'improvisation en jazz. Hervé le Nost analyse la place du couple superflu/nécessaire dans la pratique de l'art contemporain, à travers le recyclage de rebuts ou encore la notion de kitsch.

7 Le volume se clôt sur une réflexion de Cornelius Crowley qui cherche à définir une ontologie du superflu, libérée de la prééminence conceptuelle du nécessaire. Finalement, cet ouvrage collectif fournit un éclairage précieux sur une notion dont il dégage avec brio toute la complexité.

\section{INDEX}

Thèmes : Recensions

\section{AUTEUR}

NATHALIE VANFASSE

Université de Provence 